\title{
A significação da pedagogia: discursos de professores formadores e epistemologias em fluxo
}

The signification of pedagogy: discourses of teachers trainers and

epistemologies in flow

José Leonardo Rolim de Lima Severo*

Universidade Federal do Piauí

Resumo Trata-se de um artigo que apresenta reflexões em torno dos resultados de uma pesquisa de campo cujo objetivo consistiu em compreender como professores que atuam como formadores de pedagogos em uma Universidade Pública brasileira atribuem significados epistemológicos à Pedagogia. $\mathrm{O}$ processo metodológico se definiu pela realização de entrevistas semi-estruturadas com 10 (dez) professores formadores que ministravam disciplinas de Fundamentação da Educação no curso de Pedagogia e pela análise dialógica do discurso (abordagem bakhtiniana) em interação com aportes analíticos providos pela Teoria das Representações Sociais. Aborda-se que a Pedagogia está inserida no campo de significações acerca do conhecimento pedagógico, do próprio curso e da identidade profissional do pedagogo, bem como representações resultantes do processo de significação que foram identificadas no discurso dos professores formadores e os modos de incidência das mesmas na construção das perspectivas de ensino que orientam a sua ação docente.

PALAVRAS-CHAVE: Pedagogia; Significação; Discurso; Professor formador.

Abstract This is a paper that presents reflections around the results of an empirical research, whose objective was to understand how professors, who act as teachers' trainers in a Brazilian Public University, give epistemological significances to Pedagogy. The methodological process was defined by the realization of semi-structured interviews with ten (10) teachers trainers who ministered courses in Pedagogy career and by the Dialogic Discourse Analysis (Bakhtin's approach) in interaction with analytical inputs provided by the Theory of Social Representations. We approach that Pedagogy is insert in the field of significations about the pedagogical knowledge, the Pedagogy Course and the professional identity of the teachers, as well as the representations resulting from the process of signification that were identified in the discourse of teachers trainers and the incidence modes of same in the construction of educational perspectives that guide their teaching.

KEYWORDS: Pedagogy; Signification; Discourse; Teacher trainer. 


\section{Aspectos introdutórios}

O presente texto apresenta uma discussão acerca da significação da Pedagogia manifestada no discurso de professores que atuam na formação inicial de pedagogos em uma Instituição Federal de Ensino Superior. Parte do pressuposto de que tal significação, consistindo um processo simbólico de natureza psicossocial, articula, em sua constituição, referências epistemológicas ligadas às concepções de Pedagogia e representações em torno do processo formativo no curso de Pedagogia, construídas através de experiências de socialização ocorridas ao longo da história de formação e atuação profissional desses sujeitos.

A afirmação de que no processo de significação ocorre a articulação entre tipos de conhecimento distintos, mais precisamente o conhecimento científico, expresso em referências epistemológicas, e as representações sociais, concebidas como um tipo de conhecimento comum, baseia-se no pressuposto desenvolvido por Jovchelovitch (2008) quando analisa as representações sociais e a diversidade do saber, sublinhando a pluralidade da razão, o que converge para os estudos de Moscovici (2009) e Marková (2006) sobre polifasia cognitiva.

Os elementos que são mobilizados pelos professores formadores para dar significado à Pedagogia revelam três principais desdobramentos de significação: a pedagogia enquanto conhecimento, a pedagogia enquanto curso e a pedagogia enquanto profissão.

Os resultados expostos e problematizados no texto se apoiam em reflexões em torno de dados obtidos através da realização de entrevistas semi-estruturadas com professores formadores do curso de Pedagogia. Foram entrevistados dez professores de ambos os sexos, que ministraram as disciplinas de Filosofia da Educação, Sociologia da Educação, Didática, Psicologia da Educação, Fundamentos Epistemológicos da Educação e Pesquisa Educacional, no segundo semestre letivo do ano 2012. Os professores formadores têm um perfil de formação acadêmica relativamente diversificado. Todos os entrevistados são mestres e nove são doutores. No texto, os professores formadores serão identificados com a sigla formada pelas letras PF (professor formador) seguida das letras iniciais das disciplinas por eles ministradas. Vale salientar que a pesquisa em sua totalidade abrangeu outras etapas e que, portanto, configura um quadro mais amplo de reflexões.

Como pressuposto que embasa as conjecturas tecidas a partir dos dados, tem-se a noção da Pedagogia como como Ciência da e para a Educação em seus múltiplos nexos e dimensões, fundada em uma razão práxica e orientada para uma ação transformadora (SCHIMIED-KOWAZIK, 1983). A Pedagogia tende a um sentido de amplitude científica que abrange, no aspecto epistemológico, um caráter uno e múltiplo, teórico e prático, definido por seu relacionamento transdisciplinar com os conhecimentos providos por ciências auxiliares, embora mantenha-se como a única ciência capaz de articulá-los, em vista a sua vinculação com a práxis educativa, no aspecto metodológico a conjugação as dimensões descritiva, interpretativa, normativa e práxica e, do ponto de vista da construção do seu objeto, o faz de modo a abordar a educação como um fenômeno humano localizado histórico e socialmente. 


\section{Discursos sobre a Pedagogia: (des)lugares e apontamentos gerais}

Com base nos registros analíticos obtidos por meio da pesquisa que originou este trabalho, pode-se dizer que, em seu discurso, os professores formadores demonstram que a busca pela compreensão epistemológica da Pedagogia ainda não tem sido uma intencionalidade recorrente.

Esse escanteamento pode ser explicado de duas formas. A primeira se vincula ao argumento de que, estando a discussão epistemológica posta num campo de conflitos discursivos, as dificuldades de definição de um conceito para a Pedagogia levam os sujeitos a concluírem que "[...] a discussão do seu estatuto de cientificidade é diletantismo, perda de tempo ou pura filosofia” (PIMENTA, 1998, p. 41). A segunda forma explicativa do problema em tela se pauta pela ausência de experiências de formação, estudo e pesquisa dos professores formadores no que diz respeito a essa discussão.

Primeiramente, ressalta-se que os professores formadores assumem que a discussão epistemológica da Pedagogia não tem ocupado espaço relevante nas práticas de gestão institucional e de ensino no curso de Pedagogia.

Ao tempo em que reconhecem a precariedade da discussão epistemológica, os professores formadores também assumem que essa discussão é necessária para que os processos de ensino-aprendizagem no curso ocorram de modo mais qualificado e coerente com as demandas que a sociedade contemporânea faz emergir. Uma professora formadora identificada como PF-PE1 exemplifica bem essa questão quando diz que "Eu acho que a Pedagogia é uma questão que a gente tem que enfrentar na próxima reformulação do curso de Pedagogia”. Essa professora, pedagoga e doutora em área afim, demonstra reconhecer o lugar de importância que a referência epistemológica à Pedagogia deve ter no contexto da construção das perspectivas de ensino-aprendizagem e do currículo do curso, a fim de pensá-lo de acordo com as possibilidades e demandas que o atual tempo histórico inspira, o que vai ao encontro de que

O não-enfrentamento da questão epistemológica em educação dificulta aos educadores a articulação das pesquisas que eventualmente se realizam na área e a formulação de pesquisas necessárias que estão sendo indicadas pelas urgências da prática social da educação. (PIMENTA, 2000, p. 27).

Reconhecendo que a discussão epistemológica não é feita, mas que teria espaço no contexto que envolve o curso de Pedagogia, os professores formadores apresentaram, quando solicitados a falarem sobre o que significa a Pedagogia para eles, definições gerais pouco consistentes, reportando-se às representações sobre o conhecimento pedagógico, a formação e a profissão/atuação/aluno de Pedagogia. A dificuldade de conceituação epistemológica geral é evidente a partir da observação desses três trechos extraídos dos enunciados dos professores formadores:

A pedagogia é uma área de saber voltada para a discussão (pausa)... É uma área, basicamente, voltada para se discutir a questão da inserção profissional do pedagogo (pausa)... Ah! Não sei. Essa aí passa! (PF - PE2). 
Ta aí, você me pegou! (risos). Sabe que eu não sei?! Eu vejo a pedagogia como o campo das possibilidades. Essa coisa assim que, ao mesmo tempo que tem as limitações de tudo, de atuação, por outro lado ela é de verdade assim (pausa)...É...um campo de possibilidades mesmo. De aprendizagens, de conhecimento, de libertação, tipo é uma forma da pessoa conseguir status. Um termo assim, pra dizer assim Pedagogia é isso, não sei, eu não consigo dizer não (risos). $(\mathrm{PF}-\mathrm{DI})$

Ainda que observada uma dificuldade de definição epistemológica para a pedagogia, os professores formadores elaboraram alguns conceitos que se estruturavam a partir de elementos figurativos advindos de três campos de significação: a Pedagogia como conhecimento, como curso e como profissão. Logo, demonstravam construir significados diferenciados para a Pedagogia quando esta palavra se remetia a cada um dos campos e as suas respectivas representações.

\section{O conhecimento da Pedagogia em foco}

Com relação ao primeiro campo de significação, no qual foram encontradas representações sobre o conhecimento da Pedagogia, ou conhecimento pedagógico, observaram-se algumas tendências discursivas expressas na enunciação dos professores formadores.

Ao discorrerem sobre o conhecimento pedagógico, como um desdobramento do campo geral de significação da Pedagogia, os professores formadores colocaram em movimento, por meio da enunciação, elementos figurativos que ancoram representações estruturantes dessa significação num campo discursivo onde o seu objeto temático, o conhecimento pedagógico, é expresso como um tipo de conhecimento técnico-instrucional, cujo uso se dá em dinâmicas de ensino com crianças, e que é distinto de outro campo de conhecimento tido como mais abrangente e mais válido, qual seja, o conhecimento da Educação, ou conhecimento educacional.

Os professores formadores representam o conhecimento pedagógico como um saber menor, limitado e distinto do conhecimento educacional. Havendo, portanto, essa ruptura entre conhecimento pedagógico e conhecimento educacional, qual seria o objeto da Pedagogia, segundo os professores formadores, quando consideram que, distintamente a esta, existe outro campo científico denominado de Educação? Nesse aspecto, observa-se a predominância da matriz epistemológica que propõe a existência das Ciências da Educação em detrimento do que se define pela defesa da Pedagogia como Ciência da Educação. A noção de Ciências da Educação é fruto de um empreendimento acadêmico do início do Século XX que pretendia ampliar o foco das pesquisas educacionais através da subdivisão de especialidades científicas interessadas em dimensões do fenômeno educacional. Isso explica o motivo pelo qual os professores formadores não conceberam a educação como o objeto da Pedagogia e a colocaram como uma parcela da Educação, manifestada como uma área redundante do somatório de outras ciências. Nos trechos abaixo, esses aspectos da significação podem ser visualizados. 
[...] Por que a educação para mim está acima da pedagogia. Tem muito mais coisas que a pedagogia não dá conta, por exemplo entender de conjuntura social independente do que está colocado no campo da escola e ver que isso interfere na escola; entender de relações econômicas que a escola não trabalha. (PF - DI).

Eu não vejo uma ciência da educação. Eu vejo várias ciências ajudando a educação. (PF - EE1).

[...] o que a pedagogia vai discutir é, basicamente, o ensino-aprendizagem nessa discussão mais ampla que é a educação, vai lidar com questões do universo da escola. (PF - PE2).

A compreensão que dicotomiza Pedagogia, um saber sobre a educação, e educação propriamente dita se refere, numa perspectiva histórica, à primeira e à segunda etapas de constituição da Pedagogia, segundo Saviani (2008), quando ela foi, num momento inicial, confundida com a própria prática educativa e, depois, se configurou como uma meta-educação inspirada por uma filosofia soberana.

Nessa divisão entre Pedagogia e Educação, de acordo com um professor formador, a segunda teria conquistado uma possível identidade estável, enquanto que a primeira ainda permanece numa nebulosa de dúvidas e questionamentos epistemológicos. Tal discussão remete à polêmica da identidade da Educação, concebida como um campo de múltiplas ciências com enfoques diversos separado da Pedagogia. De acordo com Cambi (1999), essa dicotomização não elevou a Educação ao status de campo científico, por meio do paradigma epistemológico embutido na noção de Ciências da Educação, haja vista que a mesma se concretizou muito mais como um dispositivo de estratégia organizacional de um campo acadêmico do que como fundamento para constituição de um novo campo científico.

Analisando o discurso dos professores formadores, considera-se que a redução e simplificação da Pedagogia implicadas pela significação do conhecimento pedagógico como foi descrito decorre, também, das questões que estes sujeitos compreendem como próprias e específicas do universo pedagógico, tal como pode se depreender do trecho da enunciação do professor formador identificado como PF - PE2 inserido anteriormente.

Para os professores formadores, o universo da pedagogia é o universo da escola, das técnicas de ensino-aprendizagem, do instrumental didático-metodológico. Por mais que alguns professores formadores tenham definido a Pedagogia aproximando-a de um sentido mais amplo da educação, entendida como processo global de desenvolvimento e formação do ser humano, predominou a dimensão de um fazer, num sentido operacional, como o seu principal aspecto constitutivo, tal qual pode ser observado nos trechos a seguir.

A pedagogia para mim é a melhor forma de fazer a educação. (PF - EE2).

Eu acho que a pedagogia é uma área de saber para tornar as pessoas mais partícipes da vida social. ( $\mathrm{PF}-\mathrm{SE})$.

A pedagogia é, portanto, esse instrumental que eu vou ter que para ajudar o humano nessa potencialização do ensino-aprendizagem. (PF - EE1). 
A demarcação do espaço da pedagogia em torno das questões relativas ao universo dos modos de operacionalização e/ou instrumentalização das práticas pedagógicas reflete a concepção epistemológica do conhecimento pedagógico como um saber técnico, resultado da aplicação de formas práticas forjadas na experiência de cada indivíduo ou da modelagem operada no âmbito das ciências exógenas que the dão suporte.

Em síntese, no que tange à significação da Pedagogia na dimensão do conhecimento pedagógico, os professores formadores estabelecem claras conexões entre o modelo epistemológico das Ciências da Educação, com todas as suas fragilidades e lacunas teórico-conceituais, e representação social do conhecimento pedagógico como saber operacional-tecnológico, representação esta ancorada em elementos figurativos relacionados à escola e ao plano técnico-instrumental do processo de ensino-aprendizagem.

\section{A significação da Pedagogia pelo viés curso/formação de pedagogos}

Mantendo relações com esse primeiro campo de significação circunscrito às representações do conhecimento pedagógico, o segundo campo de significação corresponde ao binômio curso/formação em Pedagogia e refere-se ao modo pelo qual os professores atribuem significados à Pedagogia a partir de representações acerca do que é o curso, dos seus objetivos formativos e de como ele se desenvolve em termos curriculares. Esse segundo campo de significação tornou-se visível quando da identificação, feita pelos professores formadores, da Pedagogia como um curso ou como um espaço/ tempo de formação.

A representação social do conhecimento pedagógico discutida anteriormente se articula organicamente às referentes a formação pedagógica, de tal modo que a associação entre pedagogia e escola, docência e técnicas de ensino, por exemplo, reverbera no modo específico que os professores encontraram para situar o objetivo do curso como sendo dirigidos à preparação de docentes, estritamente. Um trecho ilustrativo desse aspecto pode ser lido a seguir: "a pedagogia ela é... seria assim... um curso onde as pessoas devem estar preparadas para ensinar. Dá (o curso de Pedagogia) as ferramentas para usar conforme as necessidades disso" (PF - PsE1).

Os professores formadores avaliam o curso de Pedagogia a partir de uma crítica ao currículo e aos seus objetivos formativos, discutindo que este currículo se constitui numa soma de disciplinas que formam um emaranhado de perspectivas conceituais e teórico-metodológicas. Sabe-se que as disciplinas, muitas vezes, não dialogam em torno de aspectos comuns que lhes garantam certa aproximação e familiaridade, já que a dimensão de generalidade do curso tem impedido a configuração de caracteres que definam e explicitem sua especificidade.

Os trechos transcritos a seguir servem para traçar as dimensões de como os professores formadores representam o curso de Pedagogia a partir da constatação crítica de sua natureza generalista: 
É um curso de muita generalidade, sempre foi um curso de muita generalidade. Isto complica a formação daquele estudante de Pedagogia. (PF - EE1).

[...] é como se fosse tudo e nada ao mesmo tempo. O aluno tem um pouquinho de contato com cada disciplina, só que não aprofunda nada. Então, como eu sempre digo, é um curso muito geral. (PF PsE2).

Olha, o currículo do curso de Pedagogia é por demais fragmentado e muito amplo. Acho que deveríamos definir melhor o que inserir nele para não ficar essa colcha de retalhos de várias ciências. Eu mesma acho que esse é um problema do curso. (PF - PE1).

Quando um aluno diz que faz pedagogia, as pessoas perguntam: "Mas você estuda o quê mesmo?". O que é essa pedagogia? É uma coisa muito geral, difícil de apalpar. Isso acaba refletindo no currículo do curso. É muita coisa para apenas 4 anos ou um único curso. $(\mathrm{PF}-\mathrm{DI})$

O curso de pedagogia é uma colcha de retalhos mal costurada, na minha opinião. Admiro quando os alunos da graduação conseguem se dar bem nas provas de mestrado. (PF - EE2).

A crítica à generalidade traz embutida uma tentativa de chegar até uma reflexão sobre a natureza da própria Pedagogia. Sendo assim, ainda que não delineiem uma discussão especificamente em torno da epistemologia da Pedagogia, o discurso dos professores formadores reflete a existência de uma tentativa de compreensão de algo que possa ser o núcleo duro, a essência, a matriz identitária da própria Pedagogia. A problemática é que os professores formadores processam todo esse movimento reflexivo a partir da constatação de que o que constituiria a identidade da Pedagogia, no contexto dessa crítica à sua generalidade, não é algo que possa ser definido a partir dela mesma, mas algo que está relacionado aos conhecimentos das chamadas ciências da educação.

Apoiando-se em Houssaye (2004), pode-se dizer que essa tentativa consiste, na realidade, numa das formas que, historicamente, tem desembocado na negação da Pedagogia, circunstância que oculta a prática educativa em sua totalidade como objeto de base e fragiliza o processo de institucionalização dos estudos pedagógicos, visto que desloca o foco da Pedagogia de questões mais amplas que superam o limite representado pela significação que a coloca como depósito de métodos de instrução.

A pedagogia, concebida como a disciplina necessária para articular o que se diz e o que se faz no campo da educação, desaparece em proveito de um modelo dedutivo que deseja reduzir o fazer ao dizer, o saber-fazer ao saber científico [...] Com certeza, o escravo-pedagogo libertou-se, mas ao mesmo tempo simplesmente perdeu sua identidade. De novo, viu-se negado. (HOUSSAYE, 2004, p. 18).

Quando perguntados sobre se a questão da identidade da Pedagogia se constituiria num problema a ser enfrentado pelo curso, considerando a sua atual contextura, os professores formadores se posicionaram, quase de forma majoritária, positivamente com relação à questão. Contudo, haja vista as imprecisões conceituais presentes na definição da Pedagogia, os sujeitos fizeram justificativas muito vagas, lançando mão de afirmações genéricas. 
Quatro professores se referem à relação entre teoria e prática como um aspecto problemático central do curso de Pedagogia, criticando o fato de seu currículo ser organizado mais em torno do estudo de teorias e menos em experiências e investigações no campo das práticas educativas. Houssaye (2004) enfatiza a dialeticidade entre teoria e prática como um caráter constitutivo do conhecimento pedagógico, de modo que, caso tal caráter seja ignorado, a Pedagogia não se configuraria em sua complexidade. Houssaye faz críticas sobre as novas tendências de negação da Pedagogia, situando entre essas tendências o movimento de supervalorização das práticas ou dos saberes práticos e da ação.

Quando se reivindica que a Pedagogia é, estritamente, um saber prático, ou um campo de acumulação e sistematização de saberes práticos, supõe-se que ela não teria condições de construir procedimentos metodológicos válidos e gerir um objeto próprio de estudos. Concorre-se, assim, à dissociação entre ciência e saber pedagógico e à manutenção de discursos que reduzem este último a um saber prático, cuja constituição se daria pela ordem da arte ou da experiência não-científica. Se desdobra desse ponto a ideia de que a Pedagogia é insuficiente para lidar com problemáticas complexas da educação, que ela necessita estar sob a tutela prescritiva de outros campos científicos e que a fundamentação da própria Pedagogia deve se dar em contextos exteriores a ela mesma e não a partir das relações teóricas e práticas estabelecidas em seu âmbito, a partir da imersão da investigação pedagógica nos múltiplos contextos das dinâmicas de formação humana escolares e não-escolares.

Um professor formador, inclusive, menciona que a ênfase na prática, transmutada num discurso que centraliza fazeres técnicos na constituição da função formativa do curso de Pedagogia tem acarretado na redução dos estudos mais avançados sobre os fundamentos da Educação. Esse professor formador, graduado em Filosofia e Doutor em Educação, demonstrou preocupações com relação aos impactos formativos derivados dessa redução, os quais, segundo ele, têm proporcionado a precarização da formação profissional do pedagogo e dificultado a construção de teorias pedagógicas mais consistentes, do ponto de vista da sua fundamentação científica, além de, consequentemente, ser um reflexo explícito de políticas e práticas que desintelectualizam o processo formativo no curso de Pedagogia. Segundo este professor formador

O problema é a redução que houve, nos últimos tempos, dos fundamentos. $\mathrm{O}$ curso foi baseado nas práticas...é a prática pela prática..."Como é que eu faço isso", "como é que eu faço aquilo"...com pouca base de fundamentação científica. Isso acaba levando ao empobrecimento teórico do curso de Pedagogia. (PF - FE).

Ao lado desses aspectos representacionais que emergem nos discursos dos professores formadores, elementos de significação da Pedagogia estão inseridos no terceiro campo, aquele relativo à identidade profissional do pedagogo. Quando se referiram à figura de um profissional egresso do curso de Pedagogia, o pedagogo, os professores mobilizaram elementos que apontam para a significação da Pedagogia a partir de representações sobre quem é e o que faz este profissional. 


\section{Significação da Pedagogia e a problemática da identidade do pedagogo}

Esse campo de significação é consubstanciado por formas de representação da identidade do pedagogo, em virtude de abarcar perspectivas contraditórias em torno do perfil deste profissional e do processo formativo pelo qual ele precisa passar para construir competências e atuar em determinados espaços de trabalho.

Partindo dessa consideração, cabe apresentar alguns dos trechos da enunciação dos professores formadores que abordam, direta ou tangencialmente, a questão da identidade do pedagogo para, então, discutir os elementos que confluem para a significação da Pedagogia.

[...] sempre pensando que esta turma vai atuar como pedagogo junto à infância e à juventude. Todas as minhas observações e os exercícios que eu passo estão dentro desse enfoque. (PF - PsE1).

O pedagogo é formado para tanta coisa sem uma formação específica que no final ele não está habilitado para nada. (PF - FE).

A minha disciplina dá toda uma base para esse pedagogo que vai trabalhar com infância, com crianças. (PF - PsE2).

Os alunos entram aqui para serem educadores. Eu sempre inicio a disciplina dizendo que eu quero que eles se formem bem para serem os professores do meu neto. (PF - EE2).

É preciso considerar que a multiplicidade de elementos configurados no discurso dos professores formadores acerca do pedagogo traduz a complexidade e diversidade de formas de representação do perfil identitário e das competências deste profissional. A multiplicidade consiste, em si mesma, num dado indicativo da ausência de uma perspectiva hegemônica capaz de cristalizar uma forma única de representação, o que torna a discussão sobre o pedagogo um espaço de conflitos teóricos, ideológicos e políticos, bem como uma arena onde vozes plurais se chocam, se provocam e dão origem a diálogos polêmicos.

Com base nos registros das enunciações dos professores formadores apresentados anteriormente, é possível identificar duas formas gerais de representação do pedagogo e, intrínseca a estas, elementos de significação da Pedagogia. Na primeira forma de representação, o pedagogo é tido como um profissional da Educação que desenvolve atividades em cenários escolares ou não-escolares e que passa, na contemporaneidade, por um processo de reforma de perfil identitário, incorporando novas competências para atuar em práticas educativas diversas. Essa representação é menos regular, ou seja, aparece menos no conjunto de sujeitos pesquisados, em face da segunda forma de representação, a qual se manifesta de maneira mais recorrente no discurso da maioria dos professores formadores. Essa segunda forma de representação traduz o egresso do curso de Pedagogia como um professor de crianças que atua em sala de aula por meio da docência, mas que pode, em segundo plano, desenvolver atividades especiais ligadas ao ensino escolar, como a supervisão e a gestão escolar. Os professores formadores em cujos discursos foi identificada essa forma específica de representação não usaram o vocábulo "pedagogo", visto que o egresso do curso de Pedagogia 
foi apresentado como um "professor", "docente" ou, em alguns poucos casos, como "profissional da educação".

A predominância da segunda forma de representação é compreendida, entre outros aspectos, como resultado das ingerências mantidas pelo discurso oficial de regulação do funcionamento do curso de Pedagogia, traduzido nas Diretrizes Curriculares Nacionais (DCN) e no Projeto Político-Pedagógico do curso (BRASIL, 2006). Esse discurso circunscreve o curso de Pedagogia à função de formar professores para a Educação Infantil e Anos Iniciais do Ensino Fundamental na Educação Básica, admitindo possibilidades de inserção profissional em outros campos secundarizados. As Diretrizes, ao mesmo tempo em que admitem um processo formativo que se oriente pela perspectiva de que o profissional egresso do curso pode e deve atuar na gestão de processos educativos não-escolares, concentra a dinâmica e os conteúdos da formação no âmbito da escola, mais precisamente no eixo da docência, uma "super docência" capaz de incorporar todas as modalidades profissionais praticadas por um educador.

Vale salientar que o empreendimento discursivo de significação do pedagogo como professor, o qual tem se dado desde os anos de 1980 até os dias atuais, logrou um aparente consenso por parte das entidades, instituições e pesquisadores ligados ao campo da Educação. Brzezinski (2011) chega a afirmar que a identidade contemporânea do pedagogo, que tem por base a docência, corresponde a uma forma consensual de compreensão dessa identidade, forma esta que foi precedida por outras duas formas vistas como negativas e já superadas, a identidade ambígua, referente às primeiras décadas do curso de Pedagogia após a sua emergência histórica no Brasil, e a identidade técnica, associada às reformas curriculares que se deram nos anos de 1960.

No que se refere à primeira forma de representação do pedagogo, qual seja, a que o elabora como um profissional cujo campo de atuação compreende os diversos espaços educativos escolares e não-escolares, observou-se uma maior articulação com perspectivas conceituais, diferentemente da primeira forma de representação. Isso pode ocorrer em virtude de que, para os professores formadores, romper com uma forma consensual de reconhecimento de algo, como fizeram estes professores, requer um distanciamento de representações comuns e a mobilização de novos recursos, conceitos e perspectivas que, criticando e se contrapondo ao consenso, expressem um ponto de vista renovado sobre o que se quer propor/defender. Reconhece-se o esforço de alguns professores formadores em mobilizar elementos que justifiquem e propiciem legitimidade a uma representação que, por destoar do modo de reconhecimento comum, entra em confronto com as formas típicas e consensuais de representação do pedagogo.

A representação do pedagogo como profissional da educação escolar e não-escolar apareceu atrelada à ideia de Pedagogia como uma ciência produtora de conhecimentos mais amplos e abrangentes, os quais transcenderiam a concepção de conhecimento pedagógico enquanto um saber meramente técnico-instrutivo, tal como pode ser depreendido do trecho da enunciação de um professor formador, transcrito a seguir:

O pedagogo é um gestor, um condutor. Ele não é só um professor. Isso torna o curso mais complexo porque temos que dar conta de 
muita coisa, pois a Pedagogia não é só escola, não é só professor... Ela é tudo isso e mais um pouco (risos). Pedagogia é educação e educação não é só escola. (PF - PE1).

Com efeito, a afirmação do pedagogo como um profissional que, embora mantenha íntima relação com a problemática escolar, não se limita a ela, visto que a Pedagogia é uma ciência que se volta para o objeto educação em sua totalidade e pluralidade constitutiva, requer um aprofundamento teórico e conceitual que permita aos professores formadores elaborar um significado para a Pedagogia que possa ser configurado como uma matriz de referência para a construção de perspectivas formativas mais abrangentes e solidárias com as demandas da sociedade contemporânea.

\section{Considerações finais}

Dimensionar as configurações formativas do curso de Pedagogia e delinear perfis identitários do pedagogo são empreendimentos reflexivos que, inseridos numa trama complexa de elementos mobilizados pelos professores formadores, dão visibilidade a campos representacionais nos quais a significação da Pedagogia pode ser compreendida. Essa significação adquire configurações distintas em virtude desses elementos dinamizados nas e pelas construções sócio-cognitivas dos professores e, nesse sentido, variam de acordo com a presença ou a ausência de referências epistemológicas, políticas, institucionais, entre outras, acerca das especificidades que envolvem a Pedagogia enquanto conhecimento, curso e profissão.

Compreendeu-se que essa significação se desdobra em três campos específicos e que, dada a existência de representações em cada um deles, se configura como uma prática discursiva complexa que emerge de contextos de interações entre os sujeitos professores formadores com outros sujeitos e circunstâncias ao longo de seus trajetos de profissionalização. Portanto, a significação passa a ser concebida como uma prática que se articula aos conhecimentos e referências sócio-cognitivas elaboradas no cotidiano das relações e experiências formativas, institucionais e pessoais de identificação com as questões relativas ao universo da Pedagogia, universo este que se forma como resultado da confluência dos três campos identificados.

Têm sido cada vez mais historicamente relevante ressignificar o perfil identitário e o papel social do pedagogo, cabendo ser a Pedagogia, como Ciência da Educação, nesse processo, a matriz mediadora da construção de perspectivas que orientam os processos formativos. $\mathrm{Na}$ medida em que a Pedagogia for reconhecida em sua dimensão epistemológica como ciência da e para a educação, cuja natureza corresponde à mútua e dialética relação entre teoria e prática, o pedagogo poderá adquirir um novo status profissional e sua formação passará a ser organizada a partir do pressuposto de que a experiência prática deve estar intimamente vinculada ao rigoroso estudo teórico, que também é experiência, e que a escola não se constitui como único locus de vivências formativas.

O significado da Pedagogia se encontra, nessa perspectiva, no contexto da interação teórico-prática em educação, a partir das demandas emergentes na sociedade contemporânea, que é o cenário de constituição das experiências educativas refe- 
renciadas por problemáticas reais que confrontam os processos de formação humana. O pedagogo é um profissional que mobiliza os referenciais da Pedagogia e constrói sistemáticas de intervenção nas diversas realidades educativas e o curso de Pedagogia, por conseguinte, deve ser o espaço de formação, renovação e interlocução entre os saberes e as práticas da profissão.

\section{Referências}

BAKHTIN, M. Marxismo e filosofia da linguagem. 12. ed. São Paulo: HUCITEC, 2006.

BRASIL. Ministério da Educação. Conselho Nacional de Educação. Diretrizes Curriculares Nacionais para o curso de Graduação em Pedagogia. Resolução n. 1 de 15 de maio de 2006. Brasília: MEC, 2006.

BRZEZINSKI. I. As políticas de formação de professores e a identidade unitas multiplex do pedagogo: professor-pesquisador-gestor. In: BRZEZINSKI, I. SILVA, M. A. (Orgs.). Formar professores-pesquisadores: construir identidades. Goiânia: PUCGOIÁS, 2011, p. 15-50.

CAMBI, F. História da pedagogia. São Paulo: Editora da UNESP (FEU), 1999.

HOUSSAYE, J. Para uma definição da pedagogia. In: HOUSSAYE, J.; SOËTARD, M.; et al. Manifesto a favor dos pedagogos. Porto Alegre: Artmed, 2004, p. 09-46.

JOVCHELOVITCH, S. Os contextos do saber: representações, comunidade e cultura. Petrópolis: Vozes, 2008.

MARKOVÁ, I. Dialogicidade e representações sociais: as dinâmicas da mente. Petrópolis: Vozes, 2006.

MEIRIEU, P. A pedagogia entre o dizer e o fazer: a coragem de começar. Porto Alegre: Artmed, 2002.

MOSCOVICI, S. Representações sociais: investigações em psicologia social. - 6. ed. Petrópolis: Vozes, 2009.

PIMENTA, S. G. Para uma re-significação da didática - ciências da educação, pedagogia e didática (uma revisão conceitual e uma síntese provisória). In: PIMENTA, S. G. (Org.). Didática e formação de professores: percursos e perspectivas no Brasil e em Portugal. 3. ed. São Paulo: Cortez, 2000, p. 19-76.

PIMENTA, S. G. Panorama atual da didática no quadro das ciências da educação: educação, pedagogia e didática. In: PIMENTA, S. G. (Coord.). Pedagogia, ciência da educação? - 2. ed. - São Paulo: Cortez, 1998, p. 39 -71.

SAVIANI, D. A pedagogia no Brasil: história e teoria. Campinas: Autores Associados, 2008.

SCHMIED-KOWARZIK, W. Pedagogia dialética: de Aristóteles a Paulo Freire. São Paulo: Brasiliense, 1988.

*Professor doutor da Universidade Federal do Piauí, Picos, Piauí, Brasil. 


\section{Correspondência}

José Leonardo Rolim de Lima Severo - Universidade Federal do Piauí, Campus Senador Helvídio Nunes de Barros. Avenida Cícero Eduardo, s/n, Junco, CEP: 64607-675 - Picos, Piauí - Brasil.

E-mail: leonardorolimsevero@gmail.com

Recebido em 9 de outubro de 2015

Aprovado em 17 de novembro de 2015 
